 \\ International Journal of Social Sciences and Management
}

\section{A Rapid Publishing Journal}

ISSN 2091-2986

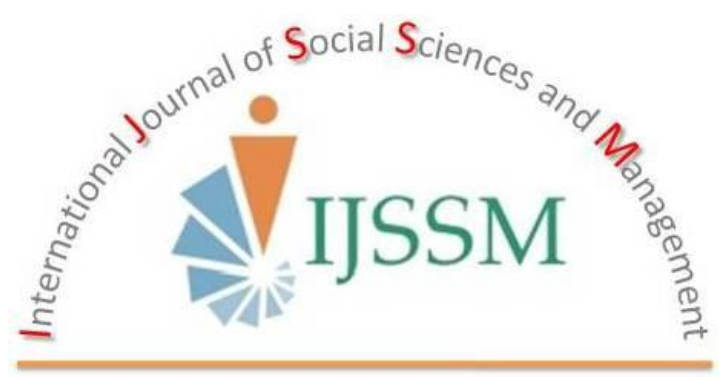

\section{Indexing and Abstracting}

CrossRef, Google Scholar, International Society of Universal Research in Sciences (EyeSource), Journal TOCs, New Jour, Scientific Indexing Services, InfoBase Index, Open Academic Journals Index (OAJI), Scholarsteer, Jour Informatics, Directory of Research Journals Indexing (DRJI), International Society for Research Activity (ISRA): Journal Impact Factor (JIF), Simon Fraser University Library, etc.

Vol-2(2) April, 2015 


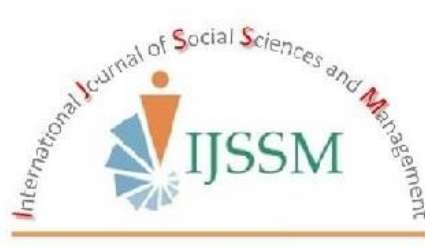

\title{
INFORMATION COMMUNICATION TECHNOLOGY AND HUMAN RESOURCE MANAGEMENT IN MODERN ORGANISATIONS: A CONCEPT FOR $21^{\text {sT }}$ CENTURY ORGANISATIONS
}

\author{
Paul Chepkuto, Stanley Kipsang* and Mwangi Kungu \\ DVC Planning and administration, Moi University, Kenya \\ Corresponding author's email: sangokip@yahoo.com
}

\begin{abstract}
Human resource information system is a database system that has been developed to provide the necessary assistance to HR in terms of decision making and reporting of information. It is basically one of the key elements that is critical in the overall management information system (MIS) of an organization. It is an IT-enabled HR service available to the HR managers for data analysis and decision making. HRIS provides the necessary support to the HR managers in making a quality decision by ensuring that there is adequate and timely relevant information that is available. The scope is so wide that it can provide information about every aspect of an employee, starting with his recruitment and ending with his retirement. As such, HRIS facilitates the use of computer technology to streamline HR operations, cut costs and eventually enhance the effectiveness of human resource management. As technology evolves, so does its impact on strategic human resource planning. Human resource information systems are electronic systems that compile information in databases to be easily accessed and analyzed. Some information systems allow automation of processes, such as payroll tax calculations, while others streamline processes by minimizing the need for manual data entry and paper records, thus increasing accuracy and efficiency
\end{abstract}

Key Words: Management Information System (MIS), Human Resources, Human Resource Information System (HRIS)

\section{Introduction.}

The genesis of human resource information systems can be traced from the 1960s, when human resource data were removed from payroll systems. During the 1980s, researchers and practitioners became more interested in human resource information systems, and in the 1990s several studies, articles, user experiences, opinions and descriptions were published in journals, magazines and on the internet. Still, despite the number of literature, no survey or framework exists that constructs a synthesis of the fragmented issues of human resource information systems from both of these viewpoints, that is, information systems and human resource management.

In regard to the growth and development of computerized management information systems in industrialized countries' enterprises in the 1980 s, HR functions began to deploy human resource information systems in their daily work. HRIS were seen as MIS sub functions within HR areas intended to support the "planning, administration, decision making and control activities of human resource management. During the 1990s, along with the adoption of more complex HR practices focused on a company's overall performance goal, HRIS has evolved into more sophisticated information expert systems featuring analytical tools to support decision-making in managing human capital which has become a transformation in the $21^{\text {st }}$ century organizations (Ostermann et al., 2009).

Information technology in the past decade has revolutionarised the human resources function. Giving the necessary support for mainly administrative activities such as payroll and attendance management in the beginning, information technology currently enhances many of the recruitment function's sub processes such as long and shortterm candidate attraction, the generation, pre-screening, and processing of applications or the contracting and bringing in of new hires. Taking into account the online job advertisements on corporate web sites and internet job boards, online CV databases, different forms of electronic applications, applicant management systems, corporate skill databases, and IS supported workflows for the contracting phase are only few examples of the various ways by which information systems currently provides the necessary 
foundation to the recruitment processes (Keim \& Weitzel, 2009).

Focusing on the HR planning process it is easier to determine workforce gaps, the quantity and quality of the labour force and to plan future workforce requirements with the help of HR knowledge management systems (Dessler, 2005). HRIS can provide the necessary support to the long range planning with information for labour force planning and supply and demand forecast; staffing with information on equal employment, separations and applicant qualifications; and development with information on training programs, salary forecasts, pay budgets and labour/employee relations with information on contract negotiations and employee assistance programmes (Shibly, 2011).Another crucial feature is the aspect of risk and security management which can be derived by HRIS by considering private and highly sensitive individual data and multiplatform security aspects which are the most crucial factors that need to be taken into account (Karakanian, 2000).

The aspect of management information system provides the necessary information for strategic, tactical and operational decision making to all subsystems within the organization. This information is critical in providing an essential part of the feedback control mechanism in these key areas and is important for the realization of subsystem objectives. Management information system can be explained as any system that provides information for management functions that are carried out within an organization. The selection and presentation of information is done in a manner that is suitable for managerial decision making and for the planning and monitoring of the organization's core functions.

\section{Human resource information system model}

HRIS model consists of 3 set of components as proposed by Raymond (1995) which is Input Subsystem, HRIS Database, and Output Subsystem. Below is the model showing the HRIS model (Fig 1)..

An observation can be made through the HRIS model containing three set of components which are Input subsystem, HRIS database, and Output subsystem. Considering the Input subsystem, there are three main subsystems which are data processing, human resource research, and human resource intelligence. Some input data might include software that can transform the data into the format that needed and required. The second component is the database; all the data and information can be store in computer storage. The software for instance Database management system) can support the performance of the maintenance processes. The last one is output subsystem which contains all the output related to HR consisting of the workforce planning subsystem, recruiting subsystem, workforce management system, compensation subsystem, benefit subsystem, and environmental reporting subsystem.

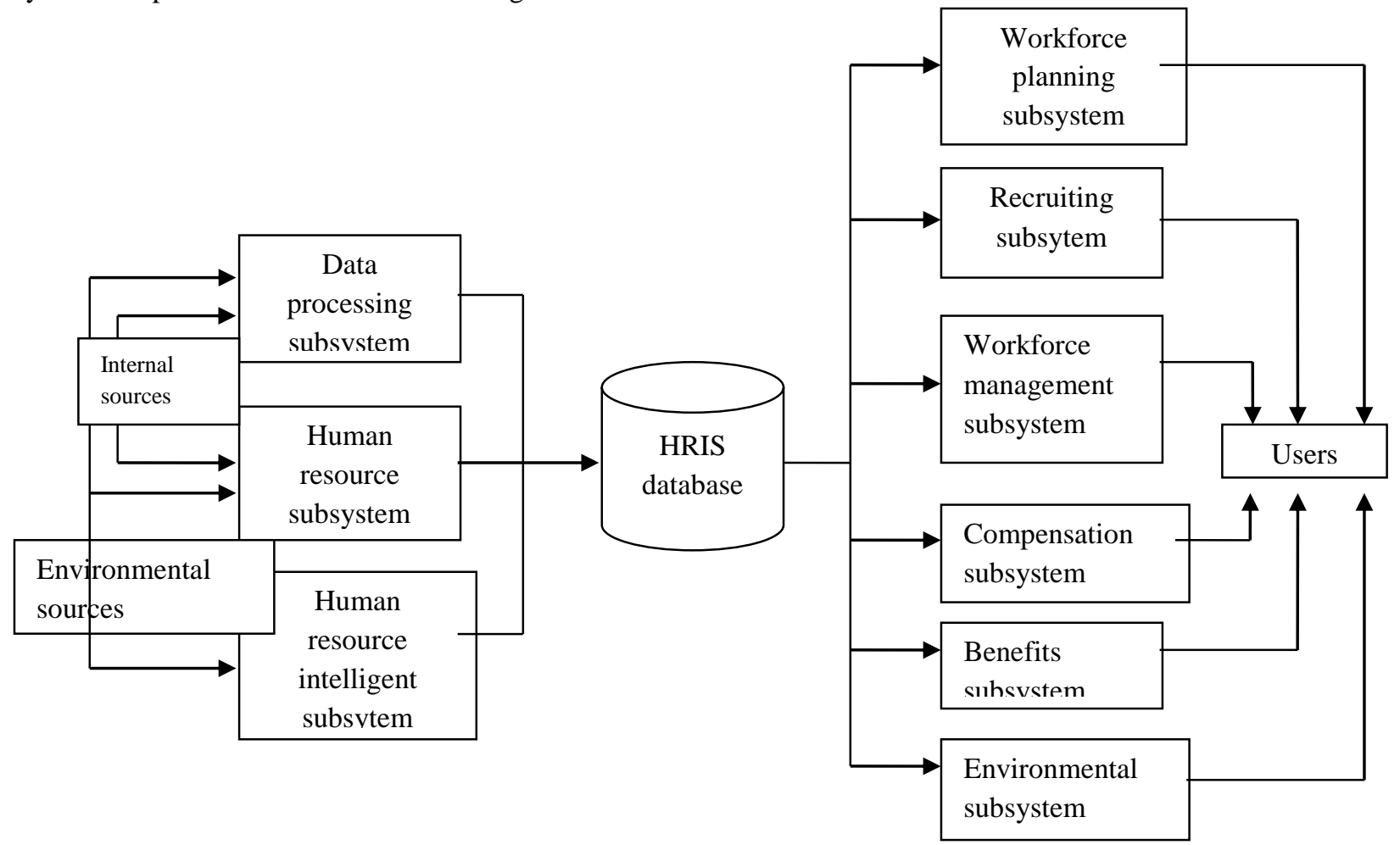

Fig. 1: HARIS model proposed by Raymond (1995)

Source; Raymond (1995) 


\section{Concept of Human Resource Information System for $21^{\text {st }}$ Century Organisations}

Human resource management information system (HRMIS) is seen as an information system that manages and provides single and centralized approach that human resource management functions needs in ensuring that human resource management process is effectively realized and sustained. This process entails the following critical aspects: recruitment and selection, time management, payroll management, performance management, reward management and employee relations management. These contains mainly a database and a database management system which can also be integrated into a more complex system that can perform a variety of Human Resource functions.

Hearthfield (2012) Defines Human Resource Information System as a software that has been integrated into overall company systems to provide organizations with a variety of solutions for the data entry, data tracking, and data information requirements of the Human Capital, payroll administration, management functions including planning; organizing; directing and controlling, and other major accounting functions within the organization. It is mainly organized into a data base where several companies can be able to market and sell these varieties of HRIS that have been developed to be able to have different capacities and provide a wide range of solutions to organizations. Taking account of this aspect, HRIS can be able to provide the necessary support in the overall management of all employee information that are critical in enhancing effectiveness and efficiency in organizational performance. It has been noted that HRIS can demonstrate performance of a number of important functions ranging from a simple storage and relay of information, to more complex and sophisticated transactions. As technology grows and develops, the variety of functions that an HRIS can perform increases tremendously. In actual fact HRIS has been geared towards the functions contained HR department itself, but in essence the usage of HRIS can give a number of advantages to the main HR functions, the line managers, and the general organization. HRIS has been seen by many as an opportunity for human resource professionals to become strategic partners with top management. It has also been seen to provide an opportunity for the HR functions to be more efficient and effective providing better information for decision making at all levels within the organization.

Several authors have conceptualized that by increasing the use of web technology to deliver HR services HR specialists will have enough time to make strategic decision and that outsourcing of people-management activities will provide an opportunity for HR specialists to concentrate on performing more strategic functions. Ulrich et al. (2008) argues that being one of the key strategic partners, the HR manager can act and coordinate activities that can be able to derive key advantages from IHRS, to be able to create opportunities in disseminating and executing the key strategies within the organization. This kind of system enables the employees to handle much of their own HR administrative work. They can be able to deal with different and several routine transactions at any given point in time. Taking into consideration their previous operational role, HR professionals can also be able to act as managers who are competent through the arrangement of the right people to the right positions in the right time, in the right manner with their new strategic architectural responsibilities. There has been a critical analysis that has conceptualized HRIS has contributing to the total business output through the fulfillment and supporting the tasks of data storage and retrieval and serving as administrative supporting tools that has immensely contributed to the overall reporting and statistical analysis as well as program monitoring and evaluation (Ostermann et al., 2009). It is worth noting that HRIS has played a crucial role in most organizations which has resulted to the effective management of the human capital. In these regard many organizations have been seen to utilize HRIS in terms of assisting them in their day to day human resources functions. It is therefore important that HRIS should be aligned to the overall organizational functions and therefore be able meet the ever changing needs of the organization and its employees so that ultimately it can be able to meet its goals and objectives (Noor \& Razali, 2011).

It is important to consider the fact that HR departments need to appreciate some of the challenges of web technology and its compatibility with the HRIS software. The importance of privacy of information should be given the top most consideration and thorough evaluation of all security measures in regard to network, servers and application should be taken into account (Karakanian, 2000). On further consideration there is likelihood that there can be undesired or unexpected forces that can have an advance effect on the performance of HRIS. These can be explained from the point of view in terms of an increase in quantity but a decline in quality of potential employees in online recruitment. It is crucial to appreciate the fact that satisfaction should be guaranteed through the use of information system. These is usually seen as a feature of IS success whereby the most important measure is its relevance, applicability and usage. The main elements in this context are characterized as the attitudes and perceptions that the user has in regard to the importance attached to the information system (Shibly, 2011).

Importance should be attached to the coordination and control of key activities and processes within a business unit, department or the organization. Emphasis should be put in ensuring that departments have their own goals and procedures which should be integrated to the overall organizational functions for the business to flourish. Organizations should be able to realize effective coordination through hiring managers with the task of 
ensuring that there is synergy in all organizational functions. The different levels of management differ in their responsibilities and information requirements which ultimately affect how they carry out their day to day functions especially in line with decision making and management responsibilities. In these regard Management information system (MIS) has been developed to aid managers and professionals to process and utilize information for the benefit of the entire organization (Ulrich, 1997).

\section{Funtions of Human Resourse Information System}

The main functions of HRIS should be able to transform the business unit, department and the entire organization. There are several functions of HRIS but there are five that have been identified as the core functions:-

\section{Payroll Administration}

This has been identified as a common characteristic of most HRIS. There are several payroll systems existing in an effective HRIS which are automated and synchronized with external the time clock while others allow managerial approval by allowing each employee to input time in and time out into the system. It is important to pay attention on the key features of the payroll system and its ability to function effectively and efficiently so that it can be able to meet the organizational requirements in terms of payroll administration and management.

\section{Benefits Administration}

Many employees have been seen spending most of their time managing their benefits. An effective and efficient HRIS should be able to eliminate this kind of time wastage by giving an opportunity to every employee to manage his or her own benefits effectively without bothering the HR manager. Taking into account the above aspect it is important for organizations to acquire an HRIS that provides an opportunity for self service which can lead to time saving and administration efficiency in terms of compensation management.

\section{Training programmes}

Training is an investment that every organization takes into serious consideration hence adequate time is required to develop appropriate training strategies that can yield a high return on investment. These can be effectively realized through having an appropriate HRIS which can aid in improving workforce performance. This means that an HRIS that contains a training system can provide an opportunity to the HR department to monitor and manage all training programmes hence a critical and an important aspect in a good HRIS.

\section{Recruitment}

Recruitment is a delicate process hence organizations through the use of HRIS can be able to save time and channel their efforts in ensuring that the process becomes a success. New recruits are important and valuable to the organization hence a lot of efforts should be concentrated in ensuring the success of the process. Therefore there is need to invest in an HRIS that will assist the organization handle every step effectively and be able to ensure a high caliber of employees are brought into the organization. HRIS should ensure that there is an improvement in the overall HR functions in terms of recruitment and selection.

\section{HR Metrics}

It is worth noting that a good HRIS should provide the organization an opportunity to evaluate and review information about the organization and the employees. This is an important feature in terms of providing the organization an opportunity to analyze the strengths and weaknesses and establish appropriate strategies for improvement.

\section{Challenges Faced by HR Managers when Implementing HRIS}

The following are some of the key problems that are being experienced by human resource managers in terms of the implementation of HRIS.

\section{Resistance to Change}

Change within organizations should be handled with care especially in technology since it can create a lot of anxiety leading to resistance amongst employees. The resistance comes in the wake that the changes to be introduced will lead to the replacement of the manpower by machines or computers which are seen to be more effective, efficient in terms of cost and performance. There is a need for the HR manger to come up with appropriate strategies to deal with the resistance in order to ensure the acceptance of the change. The perception of the employees should be changed in order for them to see technology as supportive of their work and not a deterrent.

\section{Handling Workforce Shortages}

Unemployment has brought in new challenges in terms of shortages of the required manpower hence it has become a challenge for HR managers to find employees with the right skills to handle the advancement in technology. In this regard they need to come up with strategies in terms of training to equip the employees with the necessary requisite skills. These in turn should enable them to become motivated and be able to transform themselves so that they can bring the best out of themselves in terms of handling and using the new technology.

\section{Training}

Training is critical in terms of providing the employees the expertise they require to handle the technological changes that confront the organization. This benefits the organization in the long run and employees are able to feel that they are part and parcel of the organization. The HR 
manager can be able to deal with the issue by conducting a training needs analysis which should be able to pinpoint the areas that require training. This will guide the manager in terms of coming up with an appropriate training programme that can be conducted either off the job or on the job.

\section{Managing Information}

HR managers have an important role in ensuring that the information is managed well and that there is security and privacy of information. These means that with the growth of technology the aspect of privacy and security also advances and this is also linked with changes in technology. Employees need training in order to be equipped with skills and knowledge on security and privacy matters in line with business information management. These are some of the key areas that are confronting organizations currently. This means that it is important for organizations to acquire upto-date information so that it can be able to manage and handle these challenges.

\section{Contemporary Issues}

\section{Managers}

It is important to note that HRIS provides the HR manager with information on performance and reward management, recruiting, selection and retention, team/group management, project management, and employee training and development programmes. It is also critical that HRIS needs to provide the necessary details which are important in terms of helping the HR manager make the appropriate decision that will ultimately contribute to the organization meeting its short and long term goals and objectives. These in the long run should be able to help the HR manager make the appropriate decisions in terms of executing his HR functions such as training, recruitment and selection, promotions e.t.c.

\section{Analyst}

The analyst plays a very important role in terms of analyzing information provided so that he can provide appropriate alternatives and help the HR manager make the right and the best decision. In line with the above function the analyst should be able to synthesize the information and use his skills to provide elaborate reports. This means that analyst should be able to have skills in data collection, verification and utilization and this should be linked to the employee life cycle. It should also entail an understanding on the type of data, data structure and data fields that are complete and can be utilized.

\section{HRIS Expert}

The main function of HRIS expert is to ensure that employees have access to information and tools that are important in terms of doing their jobs. HRIS experts does this by knowing what is required from HR perspective then translating them into a language that can be understood by all the interested parties.

\section{Clerical Employee}

The clerical employee needs to be able to understand the process that is required so that they can be able to enter the information and generate the reports that are needed. Clerical staff within the HR department do not provide input in regard to whether an employee can be recruited into a particular position, but their key responsibility is to ensure that the new staff is properly remunerated.

\section{Employee Self-Service}

It is important that employees within the organization have an interface with the HRIS by creating a self-service web portal or by securing an employee kiosk, these can therefore lead to the removal of an HR clerk or staff member helping with the various day to day HR record modifications and transformations.

This kind of technique can be able to encourage employees to handle their personal profiles with respect to a variety of functions, such as benefit and retirement plan and programmes, monitoring or computerized training, in addition to using HRIS-based systems to complete numerous personnel forms (Niederman, 1999).

\section{Job Seekers}

Over time it has been realized that online recruiting has been attracting potential employees who are well informed, educated, Internet savvy, and their main aim is to look for high level positions (McManus \& Ferguson, 2003). These are individuals who have been growing up with computers and these makes them very comfortable in terms of getting information from the Internet. A website that has to become successful in terms of recruitment needs, be user-friendly and provides ease in terms of navigation, hence in that regard be able to attract candidates to apply for positions within an organization by adequately demonstrating the benefits that will be accrued by joining the organization.

\section{Partner Organizations}

The partner organizations to HR functions require certain information to complete their tasks. Sourcing partners in Kenya include Manpower development, Ernst and young and Kicher and associates. It has been established that the above recruiting firms require information in regard to vacant positions to be filled which should contain job description, job specifications, the degree of competencies, the salary range and the contact information. The necessary information that has to be provided is limited to specific searches for jobs that are open and there is usually an update of information whenever it is required. This means that there is a need to have accurate data, training, and detailed security check ups wherever any information about the employee has to be sent out of the organization.

\section{Conclusion}

Technology has brought a lot of transformation and has really influenced how we handle and manage our affairs. The role of HRIS has become more strategic than ever 
before and this has ensured that there is available and timely information which has led to an improvement in service delivery. In these regard it has provided an opportunity for organizations to improve their systems in terms of data storage and utilization. This has lead to organizations becoming competitive and thereby meeting the needs and requirements of all the stakeholders. Despite the fact that there are barriers to its implementation HRIS has become critical and instrumental in ensuring that there is improvement in terms of organizational performance.

Organizations can become competitive if they can be able to absorb, apply and coordinate new technological developments. In the present environment, organization will only sustain that are able to identify consumer preferences, predict market trends, innovate new products and produce world class product and services. As a consequence of the advancement of information technologies and evolvement of HR organizations have become more competitive by reducing costs and improving productivity, quality and profitability in HRM area. Modern businesses and industries are taking suitable steps for the implementation of IT in the key area of the management of human resources by enabling the employees to make their optimum contribution to the gaining of a competitive advantage.

\section{Recommendation}

Consider the use of the data: It is critical to state as clearly as possible how the organization intends to use the software. Determine the setbacks on use of the data: There is need to list any restrictions on how the data or data findings will be utilized. The recipient needs to share, publish or disseminate data findings and reports with the approval or review of the provider.

Data confidentiality: It is important to clearly state the required processes that the receiver must use to ensure that data confidentiality is maintained. Personal information should remain confidential and must not be disclosed verbally or in writing to an unauthorized third party, by accident or otherwise.

Data security: The methods that the receiver must use to maintain data security should be clearly elaborated. Hard copies of data should be kept in a locked cabinet or room and electronic copies of data should be password protected or kept on a secure disk. The organization should recommend the use of latest version of HRIS software as it is all inclusive.

\section{References}

Dessler G (2005) Human Resource Management, Prentice Hall, UK.

Heathfield SM (2012) Human resource management systems. http://humanresources.about.com/od/glosaryah/a/haris.h tm

Karakanian M (2000) Are human resources departments ready for E-HR? Information Systems Management 17(4):1-5.

Keim $\mathrm{T}$ and Weitzel $\mathrm{T}$ (2009) An adoption and diffusion perspective on CHRIS usage. In: Coronas T \& Oliva M (Ed.), Encyclopedia of Human ResourcesInformation Systems: Challenges in E-HRM (pp. 18-23). Hershey, PA: IGI Global.

Niederman F (1999) Global information systems and human resource management: A research agenda. Journal of Global Information Management, 7(2): 33-39.

Noor MM and Razali R (2011).Human resources information systems (HRIS) for military domain-a conceptual framework, International Conference on Electrical Engineering and Informatics, 17-19 July, 2011, Indonesia.

Ostermann, Staudinger and Staudinger (2009) A review of critical success factors for ERP projects. The open information systems journal 3: 14-15.

Raymond SJ (1995) Human resource management. Brisbane: John Wiley \& Sons $2^{\text {nd }}$ eds.

Shibly H (2011) Human resources information systems success assessment: An integrative model, Australian Journal of Basic and Applied Sciences 5(5).

Ulrich D (1997) Human Resource Champions: The next agenda for adding value and delivering results. Boston, MA, Harvard Business Review Press.

Ulrich D, Younger J and Brockbank W (2008) The twenty-first century organisation, Human Resource Management, Winter, 47(4): 829-50. 